\title{
Calcium and aluminium-based fillers as flame-retardant additives in silicone matrices. I. Blend preparation and thermal properties
}

\author{
Siska Hamdani ${ }^{a}$, Claire Longuet ${ }^{a}$, José-Marie Lopez-Cuesta ${ }^{\text {a }}$, François Ganachaud ${ }^{\text {b,* }}$ \\ ${ }^{a}$ Centre des Matériaux de Grande Diffusion, Ecole des Mines d'Alès, 6 avenue de Clavières 30319 ALES Cedex, France \\ ${ }^{\mathrm{b}}$ Institut Charles Gerhardt UMR5253 CNRS/UM2/ENSCM/UM1, Equipe Ingénierie et Architectures Macromoléculaires, Ecole Nationale Supérieure \\ de Chimie de Montpellier, 8 Rue de l'Ecole Normale 34296 Montpellier cedex, France
}

\begin{abstract}
A B S T R A C T
This series investigates silicone composites with enhanced thermal behaviour for cable applications. Calcium and aluminium-based fillers introduced into silicone formulations were classified according to three categories: non-hydrated fillers such as $\mathrm{CaCO}_{3}$ (precipitated calcium carbonate and natural calcite) and wollastonite, water-releasing fillers such as calcium hydroxide, ATH, boehmite, and hydroxylfunctionalized fillers including alumina and mica. The fillers were first characterized in detail, and the thermal stability of their blends with silicone was recorded by thermogravimetric analyses. A discussion on various aspects of the filler morphology (size, microstructure, release profile with temperature) on the silicone stability is finally given.
\end{abstract}

Keywords:

Silicone

Fire retardants

Fillers

Thermal degradation

Thermogravimetry

\section{Introduction}

Since the commercialization of silicones in the 40s', silicone industries have developed a variety of products, among which polydimethylsiloxane (PDMS) is the prevailing polymer. The structure of PDMS entails a wider range of operating temperatures for silicones than for most organic elastomers [1], thus covering a variety of specifications in e.g. civil engineering, transportation, aerospace, defence, textiles, cosmetics and electrical cable applications [2-5].

Silicone applications at high temperature for heat-resistant coatings of electrical cable were made possible thanks to three unique features: i) a remarkable resistance of PDMS at high temperature (PDMS starts to degrade at $300{ }^{\circ} \mathrm{C}[6,7]$ ), ii) an outstanding reaction to fire (volatile cyclosiloxane release does not participate to the gas combustion [8]) and iii) the formation of silica ash from silicone degradation, acting as a mass transport barrier and delaying the volatilization of decomposition products [9]. Since the thus-generated silica powder is often of insufficient mechanical strength to generate a cohesive residue, several types of inorganic fillers are commonly incorporated into industrial silicone formulations, in complement to fumed or precipitated silica, to provide a better shielding effect [10].

\footnotetext{
* Corresponding author. Tel.: +33 4671472 96; fax: +334671472 20 .

E-mail address: francois.ganachaud@enscm.fr (F. Ganachaud).
}

In a recent review from the open and patent literatures, Hamdani et al. [11] described the incorporation of several types of fillers in silicone matrix in a view to improve mechanical properties, to lower production cost, and to enhance the thermal stability and fire behaviour of these composites [12]. Even if several papers have proposed ways to improve the thermal stability of silicone composites, few of these tried to correlate filler-silicone matrix interactions with their behaviour at high temperature. This series is thus devoted to the study of calcium and aluminium-based inorganic fillers as additives for a new generation of fire-resistant cables. In this first part, we describe the characteristics of the different fillers, their blending in a model silicone matrix and the thermogravimetric analyses of resulting composites. The second part will focus primarily on the content and state of the residue using a simulation of a fire test such as CR1 NFC 32070 standard test (a fire test for electrical cables in France) [13]. Finally, the third part will describe the fire behaviour of similar silicone composites in conventional fire tests using the complementary cone calorimeter and micro calorimeter techniques.

\section{Materials and methods}

\subsection{Materials}

The silicone matrix, kindly supplied by Bluestar Silicones, contains $74.4 \mathrm{wt} \%$ of vinyl-terminated polydimethylsiloxane $\left(\mathrm{M}_{\mathrm{w}}\right.$ of $550,000 \mathrm{~g} / \mathrm{mol}), 25 \mathrm{wt} \%$ of $\mathrm{D}_{4}$-modified silica and $0.6 \mathrm{wt} \%$ of 
Table 1

Physical and thermal properties of the fillers used in this study.

\begin{tabular}{|c|c|c|c|c|c|c|c|c|c|c|c|}
\hline & \multirow[t]{2}{*}{ Fillers } & \multirow[t]{2}{*}{ Formula } & \multirow[t]{2}{*}{$\begin{array}{l}\text { Chemical } \\
\text { Composition }^{\mathrm{a}}\end{array}$} & \multirow[t]{2}{*}{ Particle shape } & \multirow{2}{*}{$\begin{array}{l}\text { Mean particle } \\
\text { size and } \\
\text { deviation }(\mu \mathrm{m})^{\mathrm{b}}\end{array}$} & \multirow[t]{2}{*}{$\begin{array}{l}\text { SSA } \\
\left(\mathrm{m}^{2} / \mathrm{g}\right)^{\mathrm{c}}\end{array}$} & \multicolumn{2}{|c|}{ Density $\left(\mathrm{g} / \mathrm{cm}^{3}\right)$} & \multicolumn{2}{|c|}{$\begin{array}{l}\text { Weight loss at } 900{ }^{\circ} \mathrm{C} \\
\text { (\%) }\end{array}$} & \multirow[t]{2}{*}{$\begin{array}{l}\text { XRD Crystalline } \\
\text { form }^{\mathrm{d}}\end{array}$} \\
\hline & & & & & & & Exp. $^{e}$ & Litt. $^{\mathrm{f}}$ & $\operatorname{Exp}^{g}$ & Simul. $^{\mathrm{h}}$ & \\
\hline \multirow[t]{3}{*}{ Ca-based } & $\begin{array}{l}\text { Precipitated } \\
\text { calcium } \\
\text { carbonate (PCC) }\end{array}$ & $\mathrm{CaCO}_{3}$ & $\mathrm{CaCO}_{3}$ & $\begin{array}{l}\text { Oblate/spherical } \\
\text { (aggregates) }\end{array}$ & $0.074 \pm 0.015$ & $20.57 \pm 0.04$ & $2.67 \pm 0.01$ & 2.7 & $45.0 \pm 0.4$ & 44 & Calcite \\
\hline & Calcite & $\mathrm{CaCO}_{3}$ & $\begin{array}{l}\mathrm{CaCO}_{3}(98.0 \%) \\
\mathrm{MgCO}_{3}(0.4 \%) \\
\mathrm{Fe}_{2} \mathrm{O}_{3}(0.1 \%)\end{array}$ & Rhombohedral & $1.0 \pm 0.3$ & $6.49 \pm 0.33$ & $2.69 \pm 0.01$ & 2.7 & $43.8 \pm 0.1$ & 44 & Calcite Quartz \\
\hline & $\begin{array}{l}\text { Calcium hydroxide } \\
\text { Wollastonite }\end{array}$ & $\begin{array}{l}\mathrm{Ca}(\mathrm{OH})_{2} \\
\mathrm{CaSiO}_{3}\end{array}$ & $\begin{array}{l}\mathrm{Ca}(\mathrm{OH})_{2} \\
\mathrm{CaO}(46.15 \%), \\
\mathrm{SiO}_{2}(51.60 \%) \\
\mathrm{Fe}_{2} \mathrm{O}_{3}(0.77 \%) \\
\mathrm{Al}_{2} \mathrm{O} 3(0.34 \%) \\
\mathrm{MnO}(0.16 \%) \\
\mathrm{MgO}(0.38 \%) \\
\mathrm{TiO}_{2}(0.05 \%) \\
\mathrm{K}_{2} \mathrm{O}(0.05 \%)\end{array}$ & $\begin{array}{l}\text { Rhombohedral } \\
\text { Acicular }\end{array}$ & $\begin{array}{l}1.1 \pm 0.5 \\
7.4 \pm 6.7\end{array}$ & $\begin{array}{l}5.44 \pm 0.79 \\
3.74 \pm 1.15\end{array}$ & $\begin{array}{l}2.29 \pm 0.01 \\
2.92 \pm 0.01\end{array}$ & $\begin{array}{l}2.2 \\
2.9-3.1\end{array}$ & $\begin{array}{r}29.4 \pm 0.7 \\
1.4 \pm 0.4\end{array}$ & $\begin{array}{r}24 \\
0\end{array}$ & $\begin{array}{l}\text { Portlandite Calcite } \\
\text { Wollastonite Calcite }\end{array}$ \\
\hline \multirow[t]{3}{*}{ Al-based } & $\begin{array}{l}\text { Aluminum } \\
\text { trihydrate (ATH) }\end{array}$ & $\mathrm{Al}(\mathrm{OH})_{3}$ & $\mathrm{Al}_{2} \mathrm{O}_{3} \cdot 3 \mathrm{H}_{2} \mathrm{O}$ & Rhombohedral & $0.9 \pm 0.3$ & $6.01 \pm 0.04$ & $2.43 \pm 0.01$ & 2.4 & $35.2 \pm 0.5$ & 35 & Gibbsite \\
\hline & Boehmite & $\mathrm{AlOOH}$ & $\begin{array}{l}\mathrm{Al}_{2} \mathrm{O}_{3}(83.00 \%) \\
\mathrm{Fe}_{2} \mathrm{O}_{3}(0.02 \%) \\
\mathrm{SiO}_{2}(0.04 \%) \\
\mathrm{Na}_{2} \mathrm{O}(0.50 \%)\end{array}$ & Acicular & $0.37 \pm 0.11$ & $40^{\mathrm{i}}$ & $3.01 \pm 0.01$ & 3 & $17.7 \pm 0.1$ & 15 & Boehmite \\
\hline & $\begin{array}{l}\text { Alumina } \\
\text { Mica }\end{array}$ & $\begin{array}{l}\mathrm{Al}_{2} \mathrm{O}_{3} \\
\mathrm{KAl}_{2}\left(\mathrm{Si}_{3} \mathrm{Al}\right) \mathrm{O}_{10}(\mathrm{OH})_{2}\end{array}$ & $\begin{array}{l}\alpha-\mathrm{Al}_{2} \mathrm{O}_{3} \\
\mathrm{SiO}_{2}(51.0 \%) \\
\mathrm{Al}_{2} \mathrm{O}_{3}(32.0 \%) \\
\mathrm{K}_{2} \mathrm{O}(8.5 \%) \\
\mathrm{MgO}(0.6 \%)\end{array}$ & $\begin{array}{l}\text { Spherical } \\
\text { flake-like, } \\
\text { lamellar/platelet }\end{array}$ & $\begin{array}{l}0.013^{\mathrm{i}} \\
\quad 6.8 \pm 9.6\end{array}$ & $\begin{array}{r}94.28 \pm 0.05 \\
5.87 \pm 0.75\end{array}$ & $\begin{array}{l}\mathrm{NM}^{\mathrm{j}} \\
2.78 \pm 0.01\end{array}$ & $\begin{array}{l}4^{k} \\
2.8-3\end{array}$ & $\begin{array}{l}5.3 \pm 0.3 \\
5.5 \pm 0.1\end{array}$ & $\begin{array}{r}0 \\
-1\end{array}$ & $\begin{array}{l}\text { Aluminum oxide } \\
\text { Muscovite, } \\
\text { Kaolinite, } \\
\text { Quartz }\end{array}$ \\
\hline
\end{tabular}

a Given by the supplier, the remaining content to reach $100 \%$ in some fillers is supposed to be of water.

b From ESEM photos, using a size measuring software (see text).

c From BET measurements.

${ }^{\mathrm{d}}$ From XRD.

From He Pycnometer.

From reference [15] for all fillers but mica [16].

g Measured by TGA.

${ }^{\mathrm{h}}$ Making stoichiometric calculation according to the filler decomposition pathway (see Scheme 1)

Given by the supplier.

Non measurable.

Density of micro-sized natural alumina.

1 Could not be calculated, according to the unknown precise chemical structure. 
2.5-dimethyl-2.5-di(tertbutylperoxy)hexane as a crosslinking agent. It was specifically prepared for this study in order to avoid the presence of any other additives in the formula. On SEM micrographs, silica aggregates can be seen (Figure S1), the nature of which was confirmed by EDX mapping (vide infra). The thermal behaviour of the silicone matrix alone is in agreement with previously reported figures [14] (Figure S1). Precipitated calcium carbonate (PCC), wollastonite, and boehmite were kindly supplied by Solvay, Nyco minerals and Nabaltec respectively. ATH was purchased from Martinswerk, alumina from Evonik and mica from Kaolin International. Table 1 presents the formula and filler compositions as given by the suppliers, whereas the SEM micrographs of the different fillers are given in supporting information (Figure S2).

\subsection{Methods}

Thermogravimetric analyses (TGA) were carried out on a Perkin-Elmer 7 thermal analysis system (Perkin-Elmer, Norwalk, CT). The filler and composite samples $(10 \pm 2 \mathrm{mg}$ ) were heated in an alumina ceramic crucible from 50 to $900{ }^{\circ} \mathrm{C}$ at a heating rate of $10^{\circ} \mathrm{C} / \mathrm{min}$ under a nitrogen flow rate of $20 \mathrm{ml} / \mathrm{min}$. The simulated weight loss plots were obtained by recording experimental TG curves of the different components separately, normalizing them according to their contents in the formulation and adding them to simulate the TG curve that one would attend without synergistic effects between the different components. An example is given in Figure S1 for the Bluestar Silicones matrix. The simulated curve was obtained by overlapping the curves of silica (grey dotted curve, normalized by multiplying by 0.25 ) and PDMS (black dotted curve, normalized by multiplying by 0.744 ). One sees here that hydrogen bonding between silicone and silica provides a better experimental thermal stability of the matrix compared to the simulated TG curve (black and grey solid curves, respectively).

SEM (Scanning electron microscopy) microstructure analyses were acquired on a Hitachi S-4300 environmental scanning electron microscope (ESEM) using an acceleration voltage of $15 \mathrm{kV}$. Filler morphology and distribution at the surface and in the bulk of the composites were assessed by immersing the composite sample in liquid nitrogen and fracturing it before SEM observations. Energy-dispersive X-Ray (EDX) measurements were conducted as an integrated tool in ESEM to determine the elemental composition of residue on micrographs with a magnitude of $300 \times$. Apparent filler particle size and distribution were measured on ESEM micrographs using XT Docu program as an integrated program in ESEM.

Helium Pycnometer was used to measure the density of filler. Powder sample was weighted and then placed in the measurement chamber of pycnometer. The test was carried out using helium gas under pressure of 100-150 bar and a capillary pressure of 134.44 MPa to ensure the drainage of sample. The density of the filler was calculated according to powder standard measurements.

To measure the specific surface area of the fillers by nitrogen adsorption, small samples $(\sim 1 \mathrm{~g})$ of dry powder of fillers were degassed at $25{ }^{\circ} \mathrm{C}$ under vacuum for $800-1000 \mathrm{~min}$ to remove physically adsorbed gases (water vapour). They were then immediately analyzed in a BET (Brunauer Emmet Teller) instrument (SA 3100 , Coulter Instrument $\mathrm{Co}$ ) by weighing the samples before and after the analysis. The specific surface area values were calculated automatically by the system software and are reported as square meters per gram.

X-Ray Diffraction (XRD) analyses of finely ground filler and final residues were performed on a Bruker X-ray diffractometer using $\mathrm{Cu}$ $\mathrm{K} \alpha$ radiation.

\subsection{Sample preparation}

Composite formulations consisting of $20 \mathrm{wt} \%$ of silica and $20 \mathrm{wt}$ $\%$ of filler were prepared using a HAAKE internal mixer at a temperature of $45^{\circ} \mathrm{C}$, shear rate of $40 \mathrm{rpm}$ and mixing time of 50 min. The HAAKE internal mixer has two rotors running in a contra-rotating way to blend the filler and matrix. Thereafter, filled silicone was crosslinked under heat pressure of 90 bar at $150{ }^{\circ} \mathrm{C}$ during $15 \mathrm{~min}$ to obtain a plate of elastomer with dimensions of $10 \mathrm{~cm} \times 10 \mathrm{~cm} \times 0.4 \mathrm{~cm}$.

\section{Results}

\subsection{Filler characterizations}

Before investigating the influence of the various fillers on the thermal stability of a silicone composite, the selected calcium and aluminium-based fillers were characterized by a variety of techniques, which main results are given in Table 1.

\subsubsection{Filler morphologies and particle sizes}

The fillers presented various forms and mean particle sizes, as noted in Table 1 . The corresponding particle sizes were measured on SEM micrographs taken under magnification of $20000 \times$, except for Mica $(2000 \times)$ for which particles were too large to use such zooming (Figure S2). All fillers present a large particle size distribution. PCC is composed of big agglomerates of particles bound together, whereas calcite shows independent particles. Calcium hydroxide contains very large agglomerates, probably because of the water absorbed by these very hygroscopic particles. Wollastonite is a mix of big stone-like particles and small particles. ATH particles are hexagonal rhombohedra assembled into large blocks. Boehmite showed crystal bunches of acicular (needle-like) particles that form fragile crystalline agglomerates, and alumina is composed of spherical particles. According to supplier, boehmite and alumina have mean particle sizes of $300 \mathrm{~nm}$ and $13 \mathrm{~nm}$ respectively (for this latter, the average particle size could not be measured from ESEM micrographs analysis). (Flake-like) mica forms agglomerates of lamellar platelets but some independent particles were also found. From the mean particle size measurement of fillers obtained from ESEM micrographs, one can particularly stress out the large particle size distribution of wollastonite and mica (Table 1 ).

\subsubsection{Physical properties}

The different filler characteristics are quoted in Table 1, among which their densities, measured by He pycnometry, the specific surface area (SSA), obtained by BET, and the crystalline structures from XRD analyses. When available, these experimental values were compared with ones obtained from the literature or from simulation (see Table 1 for details).

The filler densities compared well with values mentioned in the literature. Such comparison could not be done for the alumina nanoparticles, so light and fine that, even when the measuring chamber was completely filled by the sample, its density still could not be measured by He Pycnometry. Note that PCC, composed of agglomerated nano-sized particles, exhibits the same density as calcite, a natural calcium carbonate mineral.

Specific surface area (SSA) measurements provide information about the filler surface in a view of potential interfacial interactions with the matrix. According to SSA values, alumina logically exhibits the highest SSA whereas wollastonite displays the lowest one. Calcite value is three times less than PCC.

XRD analyses confirmed the crystalline form of fillers and their impurities. Some impurities were observed in calcite, calcium 


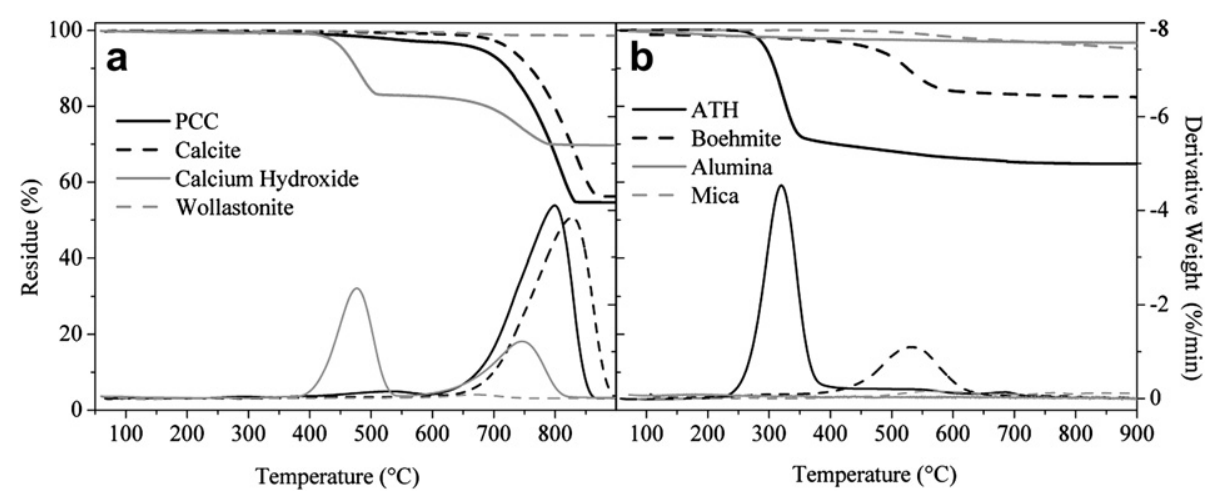

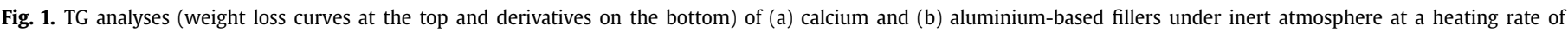
$10{ }^{\circ} \mathrm{C} / \mathrm{min}$.

hydroxide, and mica (i.e. in natural mineral products), while synthetic PCC, ATH, boehmite and alumina do not present any crystalline impurities. The most common impurities found in calcite natural mineral and in muscovite mica are quartz and kaolinite + quartz, respectively. The presence of calcite in calcium hydroxide may come from sample contamination by $\mathrm{CO}_{2}$ in atmosphere, thus reacting with $\mathrm{Ca}(\mathrm{OH})_{2}$ particles to form $\mathrm{CaCO}_{3}$ [15].

\subsubsection{Thermal stability of fillers}

The weight losses of the different fillers were determined by thermogravimetry under nitrogen at a heating rate of $10{ }^{\circ} \mathrm{C} / \mathrm{min}$ from 50 to $900{ }^{\circ} \mathrm{C}$. Experimental filler residues were compared to simulated ones from stoichiometric calculation based on the degradation pathway intrinsic to the filler structure. Fig. 1 shows the different behaviours of calcium- and aluminium-based filler under thermal treatment.

3.1.3.1. Ca-based fillers. Among all fillers, calcium carbonates showed the highest weight loss, i.e. $44 \%$, which corresponds exactly to the theoretically predicted value assuming the release of $\mathrm{CO}_{2}$ during filler decomposition (Scheme 1a). PCC produced the same final weight loss than calcite, but started to decompose at slightly larger temperature (the onset temperature of degradation is shifted of $50{ }^{\circ} \mathrm{C}$ between PCC and calcite, see Fig. 1a). Strong degradation of PCC occurred from $600{ }^{\circ} \mathrm{C}$ to $850^{\circ} \mathrm{C}$, with a derivative peak centred at $810^{\circ} \mathrm{C}$, while the main degradation event of calcite was observed from $650{ }^{\circ} \mathrm{C}$ to $900{ }^{\circ} \mathrm{C}$ (maximum derivative at $830^{\circ} \mathrm{C}$ ). The shift of temperature is either due to the difference in size of PCC and calcite, or to the natural impurities that calcite contains, such as quartz and $\mathrm{Fe}_{2} \mathrm{O}_{3}$, which may contribute to enhance the thermal stability of calcite [16-19]. It should be stressed here that $\mathrm{CO}_{2}$ release during calcium carbonate decomposition is an endothermic reaction [20].

Calcium hydroxide started to decompose in a temperature range of $400-830{ }^{\circ} \mathrm{C}$, releasing $30 \mathrm{wt} \%$ of volatiles, mainly water. Two degradation steps were observed: the first one, set between $400{ }^{\circ} \mathrm{C}$ and $600{ }^{\circ} \mathrm{C}$, released $24 \mathrm{wt} \%$ of $\mathrm{H}_{2} \mathrm{O}$, in agreement with the theoretical value (Scheme 1a). The further 6 wt\% experimental weight loss observed during the second step of degradation (between $600{ }^{\circ} \mathrm{C}$ and $830^{\circ} \mathrm{C}$ ) could be ascribed to calcite impurities seen by XRD (see Table 1), since in the TG curve, the slope of the second release coincides with those of PCC and calcite degradation (Fig. 1a).

Wollastonite should show no weight loss even after heating up to $900{ }^{\circ} \mathrm{C}$; the $1 \mathrm{wt} \%$ of weight loss observed here is tentatively explained by the presence of a small amount of calcite impurity.

3.1.3.2. Al-based fillers. The experimental weight loss of ATH filler (35 wt\%) is in agreement with stoichiometric calculation (release of three water molecules, see scheme $1 \mathrm{~b}$ ), and confirms observations from the literature [21]. ATH looses weight from $190{ }^{\circ} \mathrm{C}$ to $800{ }^{\circ} \mathrm{C}$ according to a three-step degradation scheme: the first step
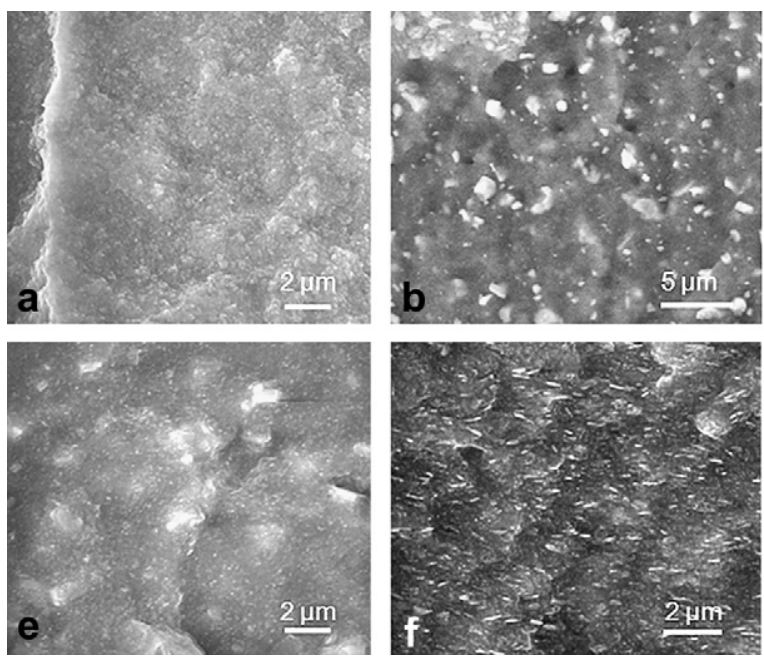
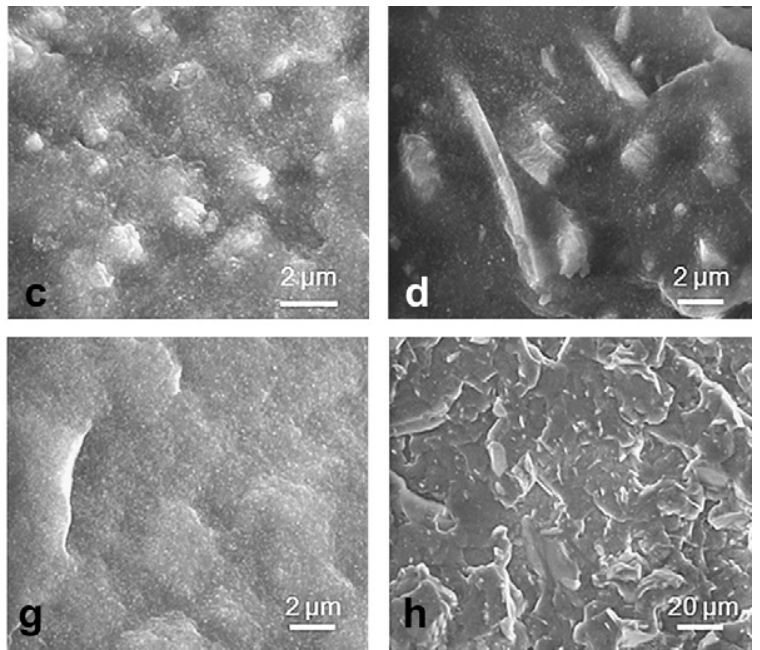

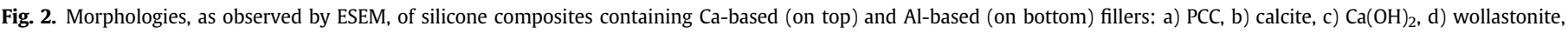
e) ATH, f) boehmite, g) alumina, h) mica. 


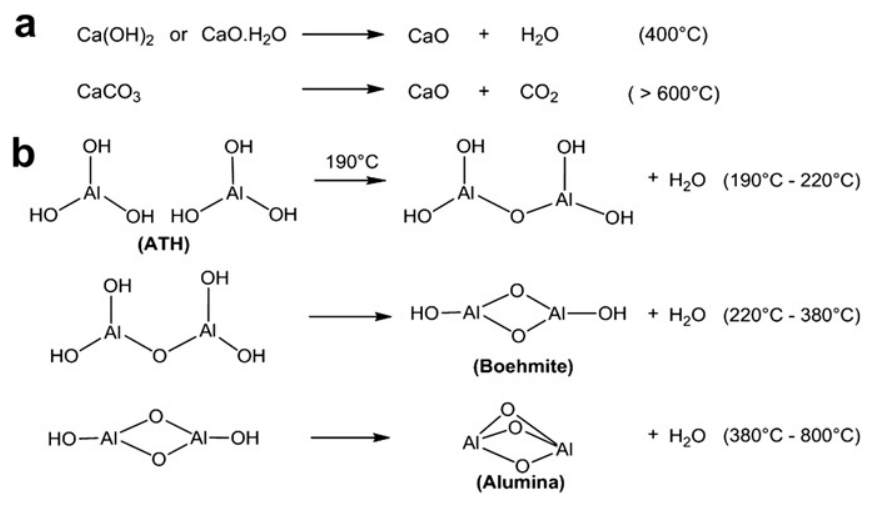

Scheme 1. Chemical degradation steps of a) Ca-based fillers and b) Al-based fillers $[21,29]$.

proceeds very slowly from $190{ }^{\circ} \mathrm{C}$ to $220^{\circ} \mathrm{C}$ (hardly visible on TG curve), the second step (strong) from $220{ }^{\circ} \mathrm{C}$ to $380{ }^{\circ} \mathrm{C}$ (peak at $320{ }^{\circ} \mathrm{C}$ ), and the third step from $380{ }^{\circ} \mathrm{C}$ to $800{ }^{\circ} \mathrm{C}$ (very slow). In a recent review, Troitzsch wrote that the degradation of ATH starts between $180{ }^{\circ} \mathrm{C}$ and $200{ }^{\circ} \mathrm{C}$ [22], whereas Hancock showed that the main degradation temperature of ATH varies with the mean particle size: fine ATH filler starts to degrade around $190{ }^{\circ} \mathrm{C}$, and coarse ATH filler degrades above $220^{\circ} \mathrm{C}$ [21]. The present TG data shows that high temperatures must be reached to degrade completely ATH, without going through a step of boehmite formation and degradation. According to Hancock and Rothon, this is probably due to the presence of some isolated hydroxyls, which need to diffuse on relatively long distances before they can react. The ATH we used here is composed of fine particles (Figure S2) in agreement with its TG profile.

Boehmite displayed similar simulated and experimental weight losses (18 wt\%), and an initial degradation temperature at $380^{\circ} \mathrm{C}$ which agrees again with the Scheme $1 \mathrm{~b}$. Strong degradation was observed from $380{ }^{\circ} \mathrm{C}$ to $550{ }^{\circ} \mathrm{C}$ (peak at $520{ }^{\circ} \mathrm{C}$ ), showing the conversion of boehmite into alumina. Alumina should not degrade even after heating at $900^{\circ} \mathrm{C}$, only a phase transition from crystalline to amorphous is expected [21]. Very low degradation of alumina filler was observed experimentally, a $5 \mathrm{wt} \%$ weight loss indebted to dehydroxylation from alumina surfaces or to the loss of lightest alumina nanoparticles during TG measurement.

Finally, mica showed a weight loss of $5 \mathrm{wt} \%$ starting from $330^{\circ} \mathrm{C}$ and going on up to temperatures of $900^{\circ} \mathrm{C}$. This weight loss is closed to the water loss reported previously in literature (4.5 wt\%) [25] and is indebted to a very slow mica dehydroxylation [23]. Indeed, water molecules are distributed among mica surface but also confined in the mica network [24]. According to Schomburg and Zwahr [25], the adsorbed water content in mica is released up to a temperature of approximately $300{ }^{\circ} \mathrm{C}$. Further dehydroxylation from $500{ }^{\circ} \mathrm{C}$ to $1000{ }^{\circ} \mathrm{C}$ occurs before achieving structural decomposition and formation of high temperature phases. The presence of kaolinite as impurity in mica was also confirmed by close observation of the TG curve, through the presence of an initial degradation temperature at $300{ }^{\circ} \mathrm{C}$ and a peak centred at $550{ }^{\circ} \mathrm{C}[26]$.

\subsection{Silicone composites}

\subsubsection{Filler distribution in silicone composites}

SEM micrographs were systematically taken to observe the distribution of the different fillers in the final composites. Fig. 2 presents all pictures taken under magnification of $20000 \times$, except for mica which magnification was $2000 \times$ to see the largest particles (to be compared with the initial matrix, Figure S1, and the filler morphologies, Figure S2).

Calcium-based fillers were easily incorporated in the silicone matrix during blending in HAAKE internal mixer. There were no neat differences of filler distribution in matrix between nano-sized (PCC) and micro-sized $\mathrm{CaCO}_{3}$ (calcite). Bigger particle size and large particle size distribution of calcite and wollastonite gave at first sight an impression of inhomogeneous blending due to the large distribution of particle size; nevertheless, while zooming on SEM analysis, a homogeneous blending was established.

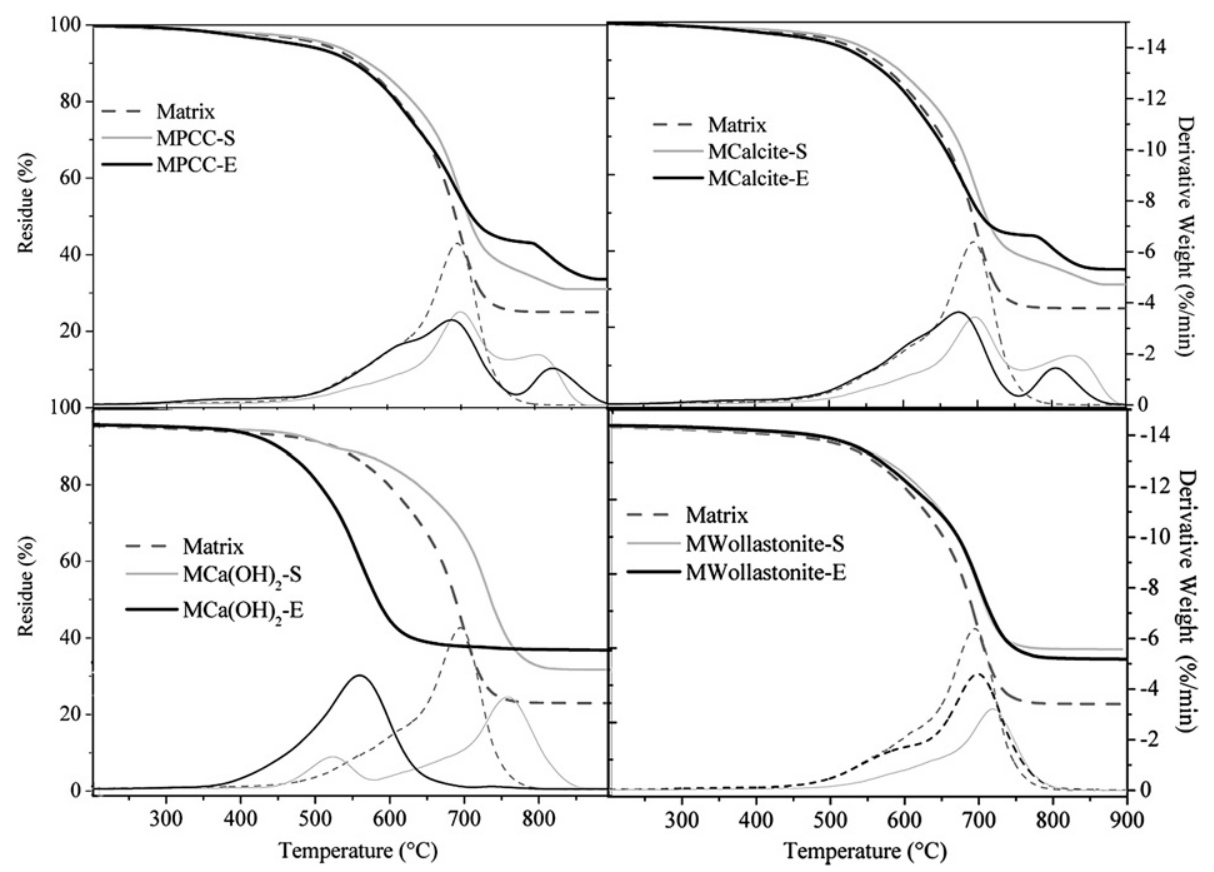

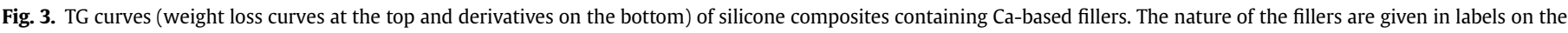
curves ( $\mathrm{S}$ = simulated curve, $\mathrm{E}=$ experimental curve). 


$\begin{array}{lrlll}\mathrm{PDMS} & \longrightarrow & \mathrm{SiO}_{2}+\mathrm{VOC} & \left(>500^{\circ} \mathrm{C}\right) \\ \mathrm{CaCO}_{3} & \longrightarrow \mathrm{CaO}+\mathrm{CO}_{2} & \left(>600^{\circ} \mathrm{C}\right) \\ \mathrm{CaO}+\mathrm{SiO}_{2} \longrightarrow \mathrm{CaSiO}_{3} \text { (Wollastonite) } & \left(800^{\circ} \mathrm{C}\right) \\ 2 \mathrm{CaO}+\mathrm{SiO}_{2} \longrightarrow \mathrm{Ca}_{2} \mathrm{SiO}_{4} \text { (Larnite) } & \left(800^{\circ} \mathrm{C}\right)\end{array}$

Scheme 2. Successive reactions in the degradation of $\mathrm{CaCO}_{3}$ silicone composites [29]. (VOC: Volatile organic compound).

Water-containing fillers (calcium hydroxide, ATH and boehmite) were also easily incorporated in the silicone matrix by mechanical blending, but their distributions in the final composite were not as homogeneous as those observed for the non-hydrated fillers. For instance, the harsh mixing conditions allowed breaking the larger aggregates of calcium hydroxide, but some agglomerates were still found in the final composite. Contrary to $\mathrm{CaCO}_{3}$-based fillers, the dispersion of hydroxyl-containing fillers in the silicone matrix seems to depend on their average particle size and particle shape: the higher the surface area, the higher the content of hydroxyl groups and the worst the filler dispersion in matrix. Some large agglomerates of alumina nanoparticles were found in silicone composite even after extensive blending, whereas massive mica flakes showed a better distribution within the matrix. The acicular shape of boehmite made its incorporation into the matrix easier than for rhombohedral-shaped fillers such as ATH or calcium hydroxide.

\subsubsection{Thermal behaviour of composites}

Even though silicone alone is known to display one of the greatest thermal stability among all elastomeric polymers (see Figure S1), some filler additions can be required when targeting demanding final fire-protective applications. Thermal stability of silicone composites were measured by thermogravimetric analyses under inert atmosphere at a heating rate of $10{ }^{\circ} \mathrm{C} / \mathrm{min}$. Experimental curves (E) were compared to simulation curve $(S)$ to see the synergistic or antagonist effect of each filler toward silicone composites (see experimental part for the description of the calculation of the simulated curve).

3.2.2.1. Ca-based composites. Silicone composites containing PCC and calcite showed an identical thermal behaviour (Fig. 3). Calcite produced slightly higher final residues (35 wt\%) than PCC (33.5 wt $\%)$, probably due to the presence of traces of other impurities in calcite such as quartz or $\mathrm{Fe}_{2} \mathrm{O}_{3}$. Indeed, transition metal oxides, such as $\mathrm{Fe}_{2} \mathrm{O}_{3}$, have been reported to increase the fire resistance of silicones $[27,28]$. Both composites degraded according to a twostep pathway, the first step starting at around $500{ }^{\circ} \mathrm{C}$, the second step from about $780{ }^{\circ} \mathrm{C}$ (with a minor variation of $20^{\circ} \mathrm{C}$ between calcite and PCC). The first degradation step occurs at the same temperature than the degradation of matrix, converting silicone into VOCs (cyclosiloxanes) and silica. Otherwise saying, $\mathrm{CaCO}_{3}$ has no influence on the thermal stability of silicone composites at low temperature (below $600{ }^{\circ} \mathrm{C}$ ). However, once $\mathrm{CaCO}_{3}$ fillers degraded into $\mathrm{CaO}$ at about $680^{\circ} \mathrm{C}$ (Fig. 3), in situ reaction between silica and $\mathrm{CaO}$ formed new crystals (typically wollastonite, calcium silicate or larnite) [29] which form a barrier layer on the surface of matrix residue (Scheme 2). This synergetic effect was confirmed by the larger residue content observed after the second step degradation (at temperatures of $800^{\circ} \mathrm{C}$ ) compared to the simulated curve (Fig. 3).

XRD analysis from residues of composites of calcium carbonate showed the formation of wollastonite and calcium silicate crystals exclusively, which minerals are $\mathrm{CaSiO}_{3}$ polymorphs. Both of them differed by their crystalline form as shown by the XRD pattern of residues of PCC and calcite silicone composites, presenting some identical peaks (Fig. 4).

Unlike $\mathrm{CaCO}_{3}$ fillers, calcium hydroxide silicone composite decomposed in one step, with an onset temperature of degradation at $400^{\circ} \mathrm{C}$, i.e. earlier than the onset of the matrix alone $\left(500^{\circ} \mathrm{C}\right)$. The final weight loss was observed as early as $650{ }^{\circ} \mathrm{C}$, with an experimental residue of $39 \mathrm{wt} \%$ against $34 \mathrm{wt} \%$ for the calculated one. As shown before, filler decomposition at $400{ }^{\circ} \mathrm{C}$ releases water which promotes earlier matrix degradation, but in the mean time it also produces $\mathrm{CaO}$ which reacts with $\mathrm{SiO}_{2}$ at high temperature, again to form new crystals, as for PCC and calcite. Since larger contents of $\mathrm{CaO}$ are available from calcium hydroxide degradation (Scheme 2), not only calcium silicate and wollastonite but also larnite crystals were tracked on the XRD pattern of the final residue (Fig. 5). Here, the experimentally observed larger residue than theoretically expected can be explained by the synergistic effect of calcite and silica that co-crystallize to form a barrier layer on the surface and limit further volatilization of the composite.

The thermally stable wollastonite slightly lowered the one-step degradation rate of the composite to produce $37 \mathrm{wt} \%$ of final residue (Fig. 3). No synergistic effect may be suggested here, since the simulated and experimental curves almost perfectly overlay on the full temperature range. Besides, the absence of in situ co-crystallization led to a slightly lower experimental final residue than the simulated curve.

3.2.2.2. Al-based composites. Fig. 6 shows the different TG curves and derivatives obtained for Al-based silicone composites. ATH silicone composite was degraded in two steps, a first slow degradation from $240{ }^{\circ} \mathrm{C}$ to $440{ }^{\circ} \mathrm{C}$, and a further rapid degradation between $450^{\circ} \mathrm{C}$ and $720^{\circ} \mathrm{C}$. ATH composites first step degradation occurred at higher temperature than ATH filler $\left(190^{\circ} \mathrm{C}\right)$, probably because some water may have been removed by silicone chain adsorption on the filler surface during the HAAKE mixing. The
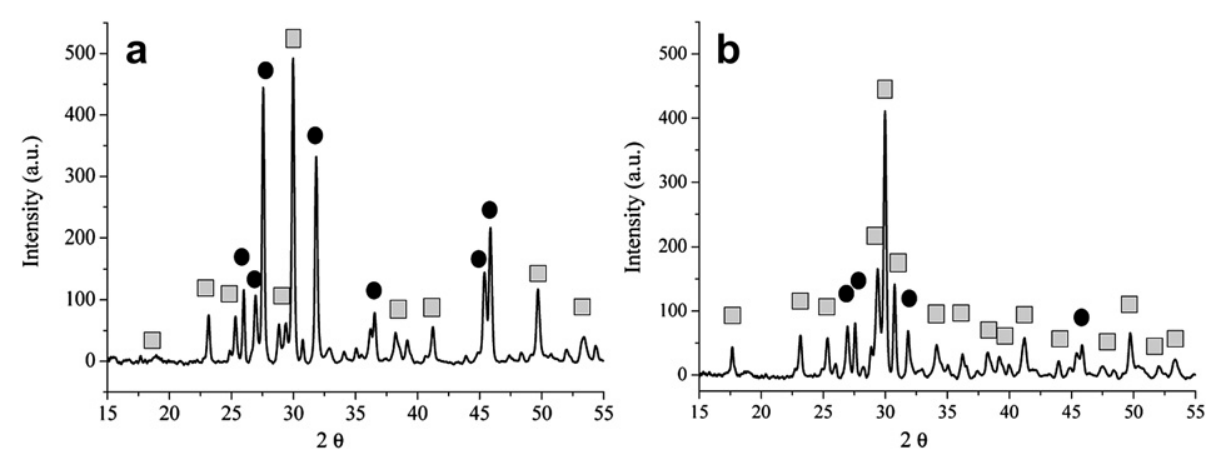

Fig. 4. XRD pattern from composite residues of (a) precipitated calcium carbonate and (b) calcite ( $\square$ Wollastonite, $\bullet$ Calcium silicate). 


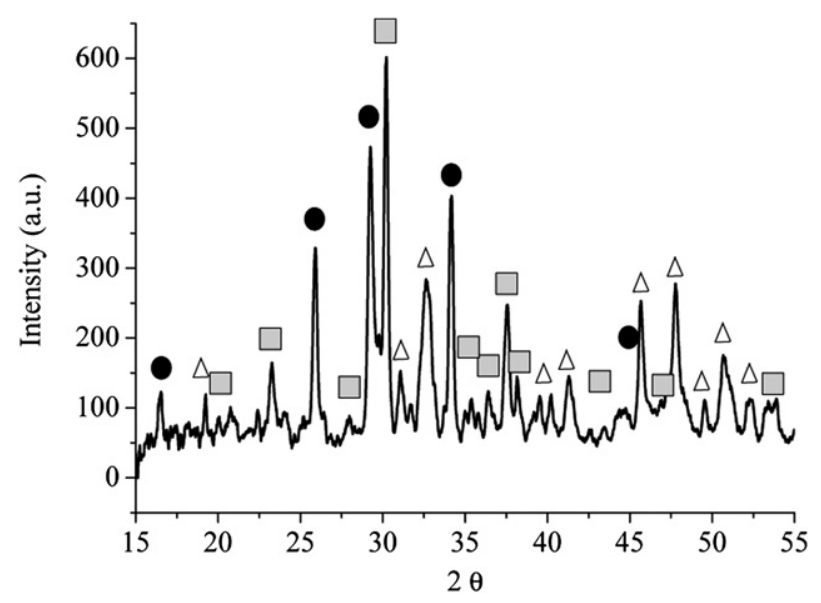

Fig. 5. XRD pattern from the residue of calcium hydroxide composites ( $\square$ Wollastonite, Calcium silicate, $\Delta$ Larnite).

weight loss observed in the first step degradation may only be caused by the filler degradation, since the simulated and experimental curves overlay quite nicely. This first step converted ATH into boehmite, so that the second step degradation was identical to that seen for boehmite decomposition. The experimental residue was slightly larger than expected (35 against $33 \mathrm{wt} \%$ ): by releasing water during its degradation, ATH probably degraded the matrix earlier to produce a silica ash layer that retarded further degradation.

Boehmite composite also degraded in two steps, with a first fast degradation from $500{ }^{\circ} \mathrm{C}$, where both filler and matrix degraded, and then a slow degradation from temperature up to $650{ }^{\circ} \mathrm{C}$ with dehydroxylation of alumina obtained from water-freed boehmite. The fact that the residue of boehmite composite is lower than expected may be explained by the large surface area developed by the filler, for which a high content of hydroxyl groups on the surface generally increases the catalytic degradation of silicone matrix through cyclosiloxane devolatilization. In addition, acicular particles of boehmite could not promote the formation of a barrier layer to limit the degradation of matrix.

Mica and alumina are both fillers that do not degrade in their bulk but only looses few percent of water by dehydroxylation of hydroxyl groups on their surface. Both mica and alumina composites were degraded through a one step weight loss and produced a final residue of about $38 \mathrm{wt} \%$. Alumina nanoparticles lowered the initial degradation temperature of silicone composites for at least $100{ }^{\circ} \mathrm{C}$ due to catalytic degradation of matrix by hydroxyl groups on the surface of alumina particles. Mica composite was degraded from $480^{\circ} \mathrm{C}$, far from the $300^{\circ} \mathrm{C}$ observed for the onset of mica dehydroxylation, presumably because its surface hydroxyl groups were engaged via hydrogen bonding with silicone chains. At temperature up to $560{ }^{\circ} \mathrm{C}$, composite degradation occurred at a faster rate than matrix alone due to mica dehydroxylation and silicone degradation. The fact that the simulated and experimental residue of mica composite coincide may be due to the fact that the mica morphology (big flake-like particles) limited volatile release through a barrier effect. Such effect was reasonably not observed for the spherical and small alumina particles.

\section{Discussion}

Several types of fillers have already been used in silicone, particularly in patents. Still, some persistent questions remain on the better filler choices for improving the thermal stability of silicone composites, especially in electrical cable applications. The present discussion, mainly relying on TG analyses, tries to correlate the thermal stability of silicone-filled composites with: i) the filler mineral-type, ii) the impact of water release from fillers iii) the filler particle size and morphology. To argue on these points, the composites were classified into three groups: 1 . Composites containing non-hydrated fillers (calcium carbonate fillers, i.e. PCC, calcite, and wollastonite); 2. Composites containing waterreleasing fillers (calcium hydroxide, ATH and boehmite); 3.

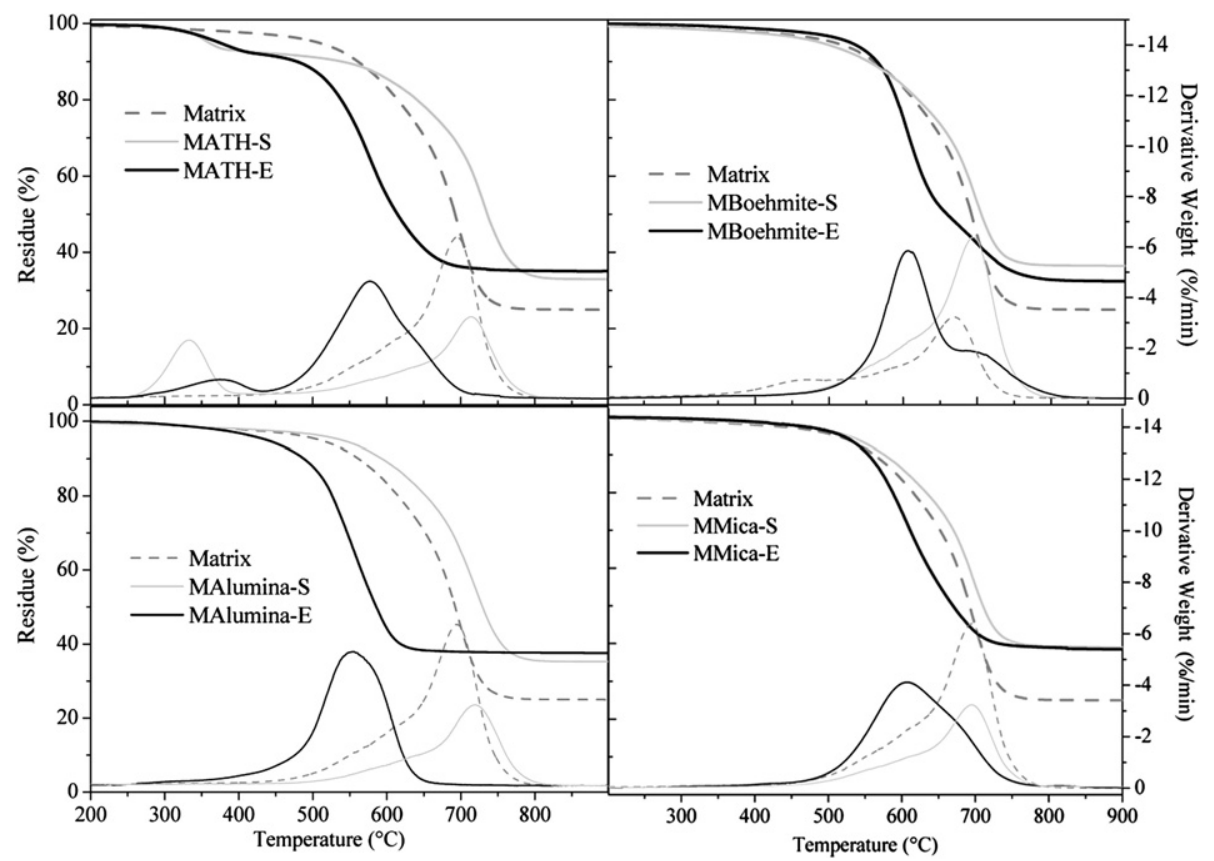

Fig. 6. TG curves of Al-based silicone composite. Fillers nature is indicated in the labels ( $\mathrm{S}=$ simulated curve, $\mathrm{E}=$ experimental curve). 


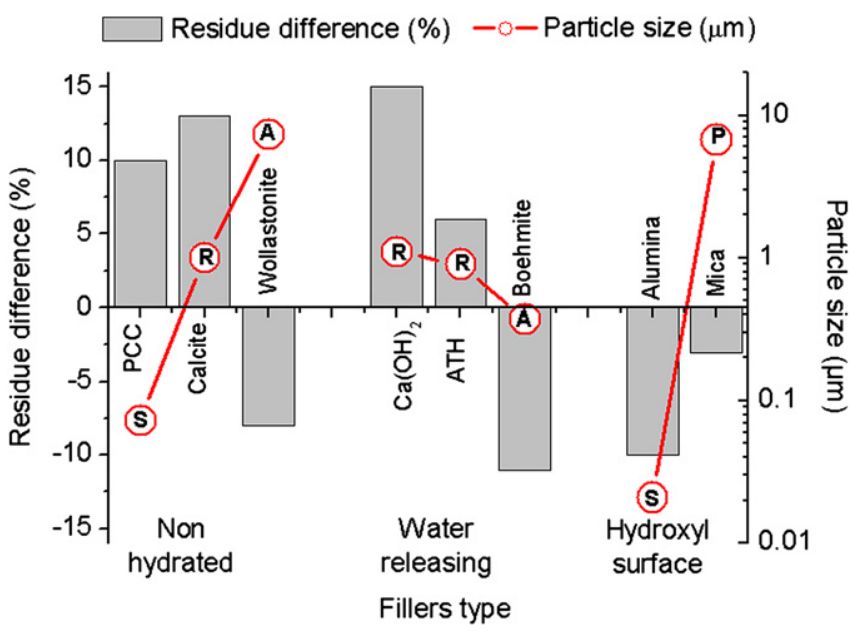

Fig. 7. Influence of particle sizes and filler morphologies on the improvement of final residue (the letter in the sphere indicates the filler morphology: $\mathrm{S}=$ spherical, $\mathrm{A}=$ acicular, $\mathrm{P}=$ platelet, $\mathrm{R}=$ rhombohedral).

Composites containing fillers with hydroxyl groups on surface (alumina and mica).

The content and mechanical resistance of the final residue are certainly the most important parameters when testing the thermal stability of electric cable-driven formulations. For this reason, we tried in this first part to correlate the nature of the fillers with the final residue of composite, especially looking at the influence of their particle size (or surface area) and morphology. Fig. 7 summarizes the effect of particle size and filler type on the final residue of the silicone composite, which variation is expressed as the residue difference $(\mathrm{R} d)$ given as:

$\mathrm{Rd}=\frac{\% \mathrm{R}_{\mathrm{Exp}}-\% \mathrm{R}_{\mathrm{Sim}}}{\% \mathrm{R}_{\mathrm{Sim}}} \times 100 \%$

where $R_{\text {Exp }}$ is the experimental residue and $R_{\text {Sim }}$ the simulated residue.

\subsection{Non-hydrated fillers}

Calcium carbonates improve the final residue of silicone composites, surely because of in situ co-crystallization phenomena between the $\mathrm{CaO}$ matter produced by $\mathrm{CaCO}_{3}$ fillers and the matrix at high temperature. The failure on the residue improvement for wollastonite composite might be caused by the absence of cocrystallization and the acicular morphology, which does not induce a heat and mass barrier as platelet, spherical or rhombohedral fillers do. Also, natural and macro-sized calcium carbonate (calcite) improved the thermal stability of silicone composites better than synthetic and nano-sized calcium carbonate (PCC). Such result was probably due to the presence of impurities in the former and also the fact that large rhombohedral particles of calcite were more efficient as heat and mass barrier than nano-sized spherical PCC particles. Since there is no obvious trend on the $\mathrm{CaCO}_{3}$ filler particle size versus silicone composite thermal stability, probably macrosized non-hydrated fillers would be economically more interesting to use than nano-sized ones.

\subsection{Water-releasing fillers}

Water-releasing fillers are a priori avoided in commercial applications since they catalyze the silicone degradation and generate cracks in the final residue $[1,30]$. However, the addition of water-releasing filler is not systematically detrimental to the composite. In fact, its effect mainly depends on numerous factors: type (aluminium or calcium-based filler), morphology, particle size, surface area, initial degradation temperature of the filler and quantity of water released by filler decomposition.

Calcium-based fillers have been shown to induce a slight synergistic effect on the final residue (PCC, calcite, and calcium hydroxide) which was not observed in silicone composites containing aluminium-based fillers. This is due to the formation of new crystals by successive in situ reactions during the degradation of $\mathrm{CaCO}_{3}$ or $\mathrm{Ca}(\mathrm{OH})_{2}$ in the silicone composites (Scheme 2). Calcium hydroxide thus presented more interesting results in terms of increasing the final residue compared to ATH or boehmite, benefiting from the co-crystallization.

Smaller particle size of water-releasing filler led to lower residue. This is correlated to a larger surface area that increases the surface contact between filler-matrix and therefore enhances the water release impact to promote thermal degradation of silicone. Besides, composites containing rhombohedral fillers show more synergistic effect on final residue than acicular fillers due to their capacity to induce a barrier effect.

Calcium hydroxide or ATH starts to degrade at lower temperature than silicone matrix, therefore the degradation of composites starts earlier with these two fillers, whereas for boehmite which starts to degrade at the same temperature as silicone matrix, no degradation of silicone composites were observed at lower temperature. Lower onset temperature of composite degradation thus leads to earlier barrier layer formation, which may retard the degradation of the matrix, to finally increase the final residue.

\subsection{Fillers with hydroxyl groups on their surface}

The presence of hydroxyl groups on the surface of alumina and mica induced an early thermal degradation of silicone composite due to catalytic activity of hydroxyl groups on the filler surface. Consequently, alumina with smaller particle size and bigger surface area degrades more silicone chains than bigger particles of mica. On the other hand, the heat barrier build by platelet mica particles at higher temperature is more effective to slow down the degradation of corresponding composites.

Considering the effect of hydroxyl groups on the thermal degradation of silicone, the surface dehydroxylation of the filler would a priori be required. Moreover, surface modification aims at facilitating the composite processing and at improving the mechanical properties of composite [31-33]. For most low-cost applications however, using large filler particles would probably be enough. Note that the substitution of non-treated silica with silane-treated silica showed only little increases both on the initial degradation temperature and on the residue of silicone composites [34].

\section{Conclusion}

Thermal degradation of silicone composite is modified by incorporating aluminium and calcium-based fillers. At high temperature, two mechanisms have been observed: i) a co-crystallization due to the reaction between the degradation products of calcium-based fillers $(\mathrm{CaO})$ with matrix $\left(\mathrm{SiO}_{2}\right)$ to form wollastonite, calcium silicate, or larnite at high temperature; ii) a barrier layer formation thanks to platelet or rhombohedral fillers which tend to limit both heat and mass transfers.

The final residue of silicone composites depends on the filler nature (non-hydrated/water-releasing/hydroxyl surface) rather than the filler type (aluminium or calcium-based fillers). For nonhydrated fillers, both morphology and reactivity with the matrix 
(co-crystallization) are important. In the case of calcium-based fillers, higher $\mathrm{CaO}$ availability resulted in better co-crystallization and increased final residue. Platelet or rhombohedral fillers were found more efficient than spherical or acicular fillers. The impurities in filler also seem to influence the thermal stability of silicone. In the case of water-releasing fillers and fillers with hydroxyl groups on surface, platelet/rhombohedral and/or micro-sized fillers increase the final residue compared to acicular and/or nanoparticles, again here, thanks to an efficient barrier effect.

The next part of this series will specifically explore the performance of final residues while burning the composites in a furnace, mimicking a French standard applied to cable fire resistance testing.

\section{Acknowledgments}

We are most grateful to Bluestar Silicones for providing all the necessary silicone raw materials to carry out this study. We also thank Solvay, Nyco Minerals and Nabaltec for donating PCC, Wollastonite and Boehmite, respectively.

\section{Appendix. Supplementary material}

Supplementary data associated with this article can be found in the online version at doi:10.1016/j.polymdegradstab.2010.04.013.

\section{References}

[1] Dvornic PR. In: Jones RG, Ando W, Chojnowski J, editors. Thermal stability of polysiloxanes: silicone-containing polymers. Dordrecht, the Netherlands: Kluwer Academic Publisher; 2000. p. 185-212.

[2] Danner B. Amino-functional silicone waxes 2009. US 7,511,165.

[3] Dubief C, Cauwet D. Utilization in cosmetic for tropical applications of an aqueous dispersion based on organosiloxanes and a crosslinked copolymer of acrylamide/neutralized 2-acrylamido 2-methylpropane sulfonic acid 2009. EP 1992, 0920, 525.

[4] Branlard P, George C, Leuci C. Polyorganosiloxane compositions vulcanisable by hot process useful in particular for making electric wires or cables 2003. EP $1,238,007$

[5] Eikhenbaum IG. Heat-resistant unit 1995. US 5,418,274.

[6] Grassie N, Macfarlane IG. The thermal degradation of polysiloxane-I poly (dimethylsiloxane). Eur Polym J 1978;14:875-84.

[7] Camino G, Lomakin S, Lazzari M. Polydimethylsiloxane thermal degradation. Part 1. Kinetic aspects. Polymer 2001;42(6):2395-402.

[8] Buch RR. Rates of heat release and related fire parameters for silicones. Fire Saf J 1991;17:1-12

[9] Hshieh F-Y. Shielding effects of silica-ash layer on the combustion of silicones and their possible applications on the fire retardancy of organic polymers. Fire Mater 1998;22:69-76.

[10] Mansouri J, Burford RP, Cheng YB, Hanu L. Formation of strong ceramified ash from silicone-based compositions. J Mater Sci 2005;40:5741-9.
[11] Hamdani S, Longuet C, Perrin D, Lopez-Cuesta J-M, Ganachaud F. Flame retardancy of silicone-based materials. Polym Degrad Stab 2009;94:465-95.

[12] Pritchard G. Fillers. Chaall, United Kingdom. In: Pritchard G, editor. Plastics additives: an A-Z reference. New York: Springer; 1998. p. 241-51.

[13] Kaufmann W, Prager FH, Schiffer HW. In: Troitzsch J, editor. International plastics flammability handbook 2nd edition: electrical engineering. Munich: Hanser Publishers; 1990. p. 344-78.

[14] Liu Y-L, Li S-H. Poly(dimethylsiloxane) star polymers having nanosized silica cores. Macromol Rapid Commun 2004;25:1392-5.

[15] Patnaik P, editor. Handbook of inorganic chemicals. New York: McGraw Hill; 2002.

[16] Utracki LA, editor. Clay-Containing Polymeric Nanocomposites, Vol. 1. United Kingdom: Rapra Technology Limited; 2004. p. 77.

[17] Criado JM, Ortega A. A study of the influence of particle size on the thermal decomposition of calcium carbonate by means of constant rate thermal analysis. Thermochim Acta 1992;195:163-7.

[18] Beruto DT, Searcy AW, Kim MG. Microstructure, kinetic, structure, thermodynamic analysis for calcite decomposition: free-surface and powder bed experiments. Thermochim Acta 2004;424:99-109.

[19] Garcia CE, Arranz MA, Leton P. Effects of impurities in the kinetics of calcite decomposition. Thermochim Acta 1990;170:7-11.

[20] L'vov BV, Polzik LK, Ugolkov VL. Decomposition kinetics of calcite: a new approach to the old problem. Thermochim Acta 2002;390:5-19.

[21] Hancock M. In: Rothon R, editor. Principal types of particulated fillers: particulate-filled polymer composites. 2nd ed. United Kingdom: Rapra Technology Limited; 1995. p. 85-8.

[22] Troitzsch HJ. In: Gachter R, Muller H, editors. Flame retardants: plastics additives. Cincinnati: Hanser Publisher; 1993. p. 709-48.

[23] Guggenheim S, Chang T-H, Koster Van Groos AF. Muscovite dehydroxylation: high-temperature studies. Am Mineral 1987;72:537-50.

[24] Sakuma H, Kawamura K. Structure and dynamics of water on muscovite mica surfaces. Geochim Cosmochim Acta 2009;73:4100-10.

[25] Schomburg J, Zwahr H. Thermal differential diagnosis of mica mineral group. J Therm Anal Calorim 1997;48(1):135-9.

[26] Murray HH, editor. Developments in clay science 2: applied clay mineralogy. Amsterdam: Elsevier; 2007. p. 180

[27] Fujiki H, Tanaka M. Silicone coated base material and air bag base material 1995. EP 0,669,419.

[28] Dubois R, Pouchelon A, Pusineri C. Use of mixtures with base of Pt and of transition metal compounds other than Pt for improving the resistance to arc tracking and to arc erosion of silicon elastomers. 1998. WO $98,029,488$.

[29] Hermansson A, Hjertberg T, Sultan B-A. The flame retardant mechanism of polyolefins modified with chalk and silicone elastomer. Fire Mater 2003;27: 51-70.

[30] Genovese A, Shanks RA. Fire performance of poly(dimethyl siloxane) composites evaluated by cone calorimetry. Compos Part A Appl Sci Manuf 2008;39(2):398-405.

[31] Yuan OW, Mark JE. Reinforcement of PDMS networks by blended and in-situ generated silica fillers having various sizes, size distributions, and modified surfaces. Macromol Chem Phys 1999;200:206-20.

[32] Osman MA, Atallah A, Kahr G, Suter UW. Reinforcement of Poly(dimethylsiloxane) networks by montmorillonite platelets. J Appl Polym Sci 2002;83: 2175-83.

[33] Park ES. Mechanical properties and processability of glass-fiber, wollastonite, and fluoro rubber reinforced silicone rubber composites. J Appl Polym Sci 2007; 105:460-8.

[34] Park SJ, Cho KS. Filler-elastomer interactions: influence of silane coupling agent on crosslink density and thermal stability of silica/rubber composites. J Colloid Interface Sci 2003;267:86-91. 